\title{
Defeasibility, Law, and Argumentation: A Critical View from an Interpretative Standpoint
}

\author{
Francesca Poggi ${ }^{1}$ (D)
}

Accepted: 7 November 2020 / Published online: 17 November 2020

(c) The Author(s) 2020

\begin{abstract}
The phenomenon of defeasibility has long been a central theme in legal literature. This essay aims to shed new light on that phenomenon by clarifying some fundamental conceptual issues. First, the most widespread definition of legal defeasibility is examined and criticized. The essay shows that such a definition is poorly constructed, inaccurate and generates many problems. Indeed, the definition hides the close relationship between legal defeasibility and legal interpretation. Second, this essay argues that no new definition is needed. I will show that from an interpretative standpoint, there is nothing special about legal defeasibility. Contrary to what some authors maintain, no unique or privileged source of legal defeasibility exists, nor are there privileged arguments to justify it. Specifically, legal defeasibility refers to interpretative outcomes deriving from interpretative arguments that, on the one hand, are very different from one another, and, on the other, are often employed to justify different interpretative outcomes. In the legal field, the problems related to defeasibility have little in common with the problems that this label covers in other areas_-such as logic or epistemology-and they are nothing but the well-known problems related to legal interpretation. In conclusion, this paper argues that as far as legal argumentation is concerned, the notion of legal defeasibility lacks explanatory power, and it should be abandoned.
\end{abstract}

Keywords Legal defeasibility · Legal interpretation · Literal meaning · Nonmonotonic logic $\cdot$ Exceptions $\cdot$ Pragmatic argumentation

Francesca Poggi

francesca.poggi@unimi.it

1 Department “Cesare Beccaria”, University of Milan, Via Festa del Perdono 7, 20122 Milan, Italy 


\section{Introduction}

The phenomenon of defeasibility has been extensively studied in different research areas, from epistemology to logic and from IA to ethics (Ross 1930; Swain 1974; Pollock 1987; Nute 1997; Nute 2003; Lance and Little 2008; Ferrer Beltrán and Ratti 2012; Koons 2017). It has long been a central theme in legal literature, where it has generated an impressive number of problems. Without claiming to be complete, I mention the following issues.

First, the literature has discussed whether all legal norms are defeasible ${ }^{1}$ - that is, are they subject to implicit exceptions that cannot be specified in advance-or whether defeasibility is a feature that distinguishes rules from principles, ${ }^{2}$ or, again, whether no legal norm is genuinely defeasible (see Rodríguez 2012).

Second, the literature debates whether a defeasible norm can be a reason for action (Redondo 2012) or whether it is not a rule at all (see Makinson 2005).

Third, controversy stems in the literature from identifying the exact sources of legal defeasibility. These sources have been identified alternately with legal principles and/or legal norms, with moral principles and/or moral norms, with the underlying reasons of a given norm, or with other phenomena still (see Schauer 1991, 1998, 2012; Bayón 2002; MacCormick 2005; Atienza and Ruiz Manero 2012; Chiassoni 2012; Dolcetti and Ratti 2016).

Fourth, the literature questions the relationship between defeasibility and legal interpretation. While according to some authors, the defeasibility of legal norms is a problem for the interpreters; according to others, it is a product of the interpreters' activity. ${ }^{3}$

Fifth, authors often debate whether defeasibility, as a necessary feature of law, can challenge exclusive legal positivism - that is, the thesis according to which law can be identified independently of any moral argument. ${ }^{4}$

Finally, the literature also addresses how to account for the logical behaviour of legal defeasible norms. In this regard, many authors are engaged in developing a non-monotonic logic — that is, a logic in which neither modus ponens nor strengthening of the antecedent is (logically) valid (Alchourrón 1996a; Nute 1997).

\footnotetext{
1 The first use of the term 'defeasibility' as well as the thesis according to which all legal standards are defeasible can be traced back to Hart (1948), but the concept of defeasibility is older. According to some authors, it dates to Aristotle (Ferrer Beltrán and Ratti 2012, p. 12), and according to others, it dates back to Plato's dialogues (Nute 1997, VII). Surely, it was first introduced in moral philosophy by Ross (1930, 19ff.) in his criticism of Kant's posture on absolute duty (in this sense, see also Ferrer Beltrán and Ratti 2012, p. 22).

2 As is well known, this position is supported by Dworkin, who claims that between legal principles and legal rules, there is a logical distinction: rules are applicable in an all-or-nothing fashion, whereas principles 'do not set out legal consequences that follow automatically when the conditions provided are met' (Dworkin 1977, p. 24).

3 On this issue see MacCormick (2005), Hernandez Marín (2012), Guastini (2012).

${ }^{4}$ For example, this view is supported by Atienza and Ruiz Manero (1998, 2012), Pérez Bermejo (2012). For arguments against, see Guastini (2010), Guastini (2012), Waluchow (2012). On this topic, see also Rodríguez (2012), Marmor (2005), Ratti (2009).
} 
This essay does not directly engage with all the above issues, but it aims to shed light on some of them by clarifying their conceptual basis. In fact, the above listed debates are complicated by the fact that the notion of legal defeasibility is neither clear nor unanimous. According to a widespread definition, legal defeasibility is that phenomenon for which a legal norm is subject to implicit exceptions that cannot be exhaustively listed ex ante (see Alchourrón and Bulygin 1996; Bayón 2002; Ferrer Beltrán and Ratti 2012; Guastini 2012; Rodríguez 2012; Marmor 2016). However, I will argue that such a definition is poorly constructed, inaccurate and generates many problems. Specifically, it obscures the close relationship between legal defeasibility and legal interpretation.

Of course, other definitions circulate in the legal literature. So, for example, according to a different view, a legal norm is defeasible if it has negative conditions of application (see Chiassoni 2012, p. 175). A different approach connects legal defeasibility to the presence of exceptions, no matter if implicit, expressed, openended, or close-ended (see D’Almeida 2015). ${ }^{5}$ Or, again, a more general definition maintains that legal defeasibility comprises 'all different way in which certain legal conclusions may need to be abandoned, though no mistake was made in deriving them' (Prakken and Sartor 2004, p. 118). ${ }^{6}$ I will not examine all these alternatives, but I will try to show that there is no need for a new definition. Legal defeasibility refers to interpretative outcomes deriving from interpretative arguments that, on the one hand, are very different from one another and, on the other, are often employed to justify different interpretative outcomes. Therefore, if from the standpoint of the interpretative outcomes, we could redefine 'defeasibility' to refer to a unique interpretative result, we cannot do so from the standpoint of legal argumentation. In other words, from the standpoint of legal argumentation, there is nothing peculiar about legal defeasibility.

My argument will proceed through the following stages. To begin with, I will present some examples of legal defeasibility in order to clearly explain the phenomena under discussion (Sect. 2). Then, I will examine and criticise the most widespread notion of legal defeasibility, arguing that it is untenable for at least five reasons ( $\S 3 \mathrm{ff}$.$) . Finally ( \S 4 \mathrm{ff}$.$) , I will argue that it is not useful to propose a new definition$ of legal defeasibility because under this label very heterogeneous phenomena are contained. I will show that the 'defeasibility' label refers to interpretative outcomes that are justified by appealing to very different interpretative arguments, which, in their turn, are often employed to support non-defeasible interpretations. This implies that from an argumentative standpoint, legal defeasibility is not a unique,

\footnotetext{
${ }^{5}$ D'Almeida (2015) adopts a peculiar and very sophisticated notion of 'exception', which does not amount to that of negative condition of application. See Sect. 3.3 below.

6 Sometimes, legal defeasibility is referred not to norms but to normative formulations (texts), facts, concepts, reasoning, conclusions, etc. For a critical analysis of these views, see Chiassoni (2012). Instead, Marmor (2016) distinguishes between three main types of legal defeasibility: legal inferences based on presumptions, legal inferences involving (open-ended) exceptions to legal rules and legal inferences about the content of legal rules, i.e. the defeasible inference through which the hearer grasps the pragmatically enriched content communicated by the speaker. For an overview of all the different meanings of 'defeasibility', see Redondo (1997) and Rodríguez (2002) (chap. IV).
} 
well-defined phenomenon. A defeasible interpretation can be justified in many ways, and legal defeasibility has many different sources. The problems connected to legal defeasibility should be usefully turned into the more general problems related to legal interpretation and interpretative arguments. It follows that if we are interested in legal argumentation, the notion of defeasibility lacks explanatory power, and it should be dismissed.

\section{The Phenomena under Discussion: Some Examples of Legal Defeasibility}

There are several examples of legal defeasibility in literature; here, I will present five of them. They are selected not only because of their dissemination but also because they highlight interesting issues.

Probably the most famous example of legal defeasibility is that of Bologna's barber. A statute in Bologna stated that 'Whoever drew blood in the streets should be severely punished'. A barber opened by mistake the vein of a person in the square. ${ }^{7}$ Should the statute be applied to that case? Obviously, many of us would argue that it should not be applied; in this case, judges must defeat the rule and must consider this case as an implicit exception to the rule.

A second and popular example of legal defeasibility is provided byUnited States vs. Church of the Holy Trinity. ${ }^{8}$ The defendant, the Church, had been prosecuted for violating a federal law prohibiting any U.S. employer from paying for the passage of an alien employee from a foreign country to the U.S. for the purpose of taking up employment. In this case, the payment was part of the process of hiring a new pastor. The Church was acquitted because judges 'cannot think Congress intended to denounce with penalties a transaction like that in the present case. It is a familiar rule that a thing may be within the letter of the statute and yet not within the statute because not within its spirit nor within the intention of its makers' (143, US 460). A lot of arguments were invoked in order to justify this verdict, ${ }^{9}$ but the main one was as follows: "no purpose of action against religion can be imputed to any legislation, state or national, because this is a religious people. This is historically true. From the discovery of this continent to the present hour, there is a single voice making this affirmation' (143, US 466). Therefore, in this case, the federal norm was defeated, and an implicit exception was established.

\footnotetext{
7 The case was firstly reported by Pufendorf (1688), Book V, Ch. 12, §8. According to a different version of the same story, the problem was to apply the legal provision in question to a surgeon who opened the vein of the person that had fallen in the street in a fit. Atria (2001, p. 117, footn. 3) hypothesizes that the origin of this second version is to be found in United States v. Kirby, 74 US (7 Wall) 482, 487 (1868), where Justice Field replaced 'barber' with 'surgeon' in his own opinion. For a discussion of either version see, e.g., Schauer (1991), Atria (2001, 177ff.), Atria (1999), Rodríguez (2012, 99), Ratti (2015).

8143 U.S. 457 (1892). The case is discussed, among many, by Schauer (2009, p. 25-26), Alchourrón (1996b), Dolcetti and Ratti (2016), Feteris (2016), Gales and Solan (2020).

${ }^{9}$ For a detailed analysis see Feteris (2016), Gales and Solan (2020).
} 
A third example is provided by Guastini (2012). In the Italian republican constitution, which is a rigid constitution, ${ }^{10}$ a provision grants to the president of the republic the power of veto over parliamentary statutes. According to a literal interpretation, the president can veto any parliamentary statute. However, is that provision also applicable to constitutional statutes? Many jurists answer in the negative. They argue that the function of veto power is to allow the president to exercise a priori control over the constitutionality of statutes, and, therefore, it makes no sense to apply this power to the constitutional statutes. Constitutional statutes are not required to comply with the Constitution, since they are constitutional amendments that can change the Constitution. Therefore, constitutional statutes are implicitly subtracted from the presidential veto power, and they represent an implicit exception.

The fourth example is not widely discussed, but it is interesting, since it clearly involves a conflict between legal principles. In Italian law, there is a criminal provision about defamation incriminating anyone who when communicating with other people offends the reputation of another person. This provision is consistent with the constitutional right to honour but inconsistent with the constitutional freedom of the press. Italian judges have resolved this conflict by balancing the two constitutional principles and establishing that the freedom of the press must prevail when the news is true and in the public interest. The outcome of such balancing can be reconstructed by saying that an implicit exception is added to the criminal norm about defamation. As a result, anyone who when communicating with other people offends the reputation of another person must be sentenced for defamation except when the news is true and in the public interest.

The last example is still taken from Italian jurisprudence. The par. 235, n. 2, of the Italian Civil Code provides the power to exercise paternity denial if, during the period of conception, the husband was suffering from impotence, even if only to generate'. In the constitutional judgment n. 347/1998, the Italian Constitutional Court established that this provision did not apply in the case of heterologous fertilisation. This decision can be understood as the introduction of an exception to the meaning of the legal provision at hand-an exception justified by the fact that, otherwise, this provision would have violated a series of constitutional principles (expressed by the par. 2, 3, 29, 30 and 31/2 of the Italian constitution) about human rights, the protection of the family and parental responsibility.

In the following sections, I will return to consider the most common notion of legal defeasibility in order to highlight its problems.

\section{Against the Widespread Notion of Defeasibility}

As we have seen, according to a widespread definition, legal defeasibility is the phenomenon according to which a norm is subject to implicit exceptions that cannot be exhaustively listed ex ante. I will argue that this notion is untenable for at least five

\footnotetext{
10 A rigid constitution is a constitution that cannot be amended through the ordinary legislative procedure, but whose amendment requires a more complex constitutional procedure.
} 
reasons: (i) it obscures the close relationship between the phenomena and the legal interpretation (Sect. 3.1); (ii) it seems to assume a notion of literal meaning that is puzzling (Sect. 3.2); (iii) the notion of 'exception' is not clear (Sect. 3.3); (iv) it is not clear how to trace the distinction between explicit and implicit exceptions (3.4); and, finally, (v) it is not clear what it means that an exception cannot be 'exhaustively listed ex ante' (Sect. 3.5).

\subsection{An Interpretation-Based Account of Legal Defeasibility}

What is the relationship between the most common notion of legal defeasibility and legal interpretation? As I have anticipated (Sect. 1), defeasibility can be seen either as an interpretative problem or as a product of the interpreters' activity. Seeing defeasibility as an interpretative problem means that the interpreter, faced with a given legal norm, is in trouble because she does not know whether that norm can be defeated by implicit exceptions. That is to say, the interpreter does not know whether the norm specifies the necessary and sufficient conditions of a given legal effect. The interpreter cannot know this, since these potential exceptions would be implicit and not exhaustively listed ex ante. In this scenario, the problem is: what do we mean by saying that the interpreter is facing a 'given legal norm'? Which norm are we referring to by saying that the interpreter cannot know whether it is defeasible? Here, it is important to distinguish between two meanings of 'norm'. According to the first meaning, 'norm' refers to a normative formulation-a text or a legal provisionwhile, according to the second meaning, it refers to a normative meaning or content.

If we take the first meaning of 'norm', the situation presented above can be modified in two different ways. First, we can say that the interpreter, facing a given legal provision, is in trouble because she does not know whether that legal provision can be defeated by implicit exceptions. This first variation raises some problems. Against the view that refers defeasibility to legal provision, Chiassoni (2012, p. 166) and Guastini (2012, p. 190) convincingly object that legal texts, considered apart from any interpretation whatsoever, are purely syntactic entities, and syntactic entities are inert. Legal provisions, considered as texts, cannot state necessary and sufficient conditions of a given legal effect, and therefore, they cannot be defeated.

Second, we can say that the interpreter, facing a given legal provision, is in trouble because she does not know whether the normative meaning that that legal provision expresses can be defeated. The problem with this second variation is that it suggests a formalist approach to legal interpretation-an approach according to which every legal provision expresses only one meaning that the interpreter must discover. In the current debate, this approach is widely discredited, and it has almost no supporters ${ }^{11}$; thus, I will not discuss it here. I only stress that if we admit that

\footnotetext{
11 The formalistic approach is not too far from the position advocated by Marmor (2005). Marmor distinguishes the plain understanding of the literal or ordinary meaning of a legal provision from the interpretation of a legal provision. Marmor maintains that interpretation is an activity that 'concerns those aspects of communication which are under-determined by semantic rules and conventions' (17), 'has to do with determining the meaning of that which is in some relevant respect unclear or indeterminate' (95) and, therefore, it 'is required only when the formulation of the rule leaves doubts' (p. 118). According to Marmor (2005), legal norms are indefeasible, except when the formulation of the rule is unclear. For a criticism of Marmor's distinction about interpretation and understanding, see Poggi (2007). Moreover, it
} 
every legal provision can express more than one norm, depending on various possible interpretations, we must specify which norm we are referring to, and we have to admit that this norm is the product of a given interpretation.

Now, consider the second meaning of 'norm' as a normative meaning -that is, as the meaning content of a legal provision. Henceforth, I will use 'norm' only in this second sense. If we adopt this second meaning of 'norm', the scenario above is to be modified as follows: the interpreter, facing a given legal norm, i.e. a normative meaning, is in trouble because she does not know whether that legal norm can be defeated by implicit exceptions. There is no problem with this variation if we admit that the legal norm in question is itself a product of legal interpretation (a legal interpretation produced by the same interpreter or by another one); otherwise, we will stumble again into a formalistic approach. Here, we should also specify what kind of norm - of normative meaning-we are talking about. In fact, it seems that in the current legal debate, not every defeating interpretation of a given meaning is labelled as 'defeasibility'. As the above examples show (Sect. 2), in the current debate, the defeated norm seems to be a literal meaning, which is, in in turn, the product of a literal interpretation of a given legal provision. Therefore, it seems that to wonder whether a norm is (or should be) defeasible is tantamount to asking whether a given legal provision is (or should be) interpreted according to its literal meaning, or, instead, whether it is (or should be) interpreted according to a particular non-literal interpretation.

To sum up, to say that a norm is defeasible is an improper way of saying that a certain legal provision has not been interpreted in a literal way. Defeasibility is the product of a given interpretation, and it seems to consist of a peculiar non-literal meaning. Strictly speaking, defeasibility is not an interpretative problem. Alternatively, and more clearly, it is an interpretative problem only in the sense in which to decide how to interpret a legal provision-particularly whether to interpret it literally or not-is always an interpretative problem. Therefore, henceforth, I will not speak of 'defeasible norm'; instead, I will speak of 'defeasible interpretation'.

As it is well known, the notion of 'legal interpretation' is itself problematic [see, e.g., Tarello (1980, p. 39-42), Barnes (1988, p. 7), Sunstein (2015), Chiassoni (2019, p. 18)]. It is heatedly debated about what legal interpretation amounts to, and, therefore, what is the relationship between legal interpretation and ordinary understanding, which is the correct legal interpretative criteria, and about how to draw the line between interpretation and the creation of law. ${ }^{12}$ Moreover, the expression

\footnotetext{
Footnote 11 (continued)

is not clear whether Marmor's thesis about defeasibility is descriptive (a thesis about what legal actors do) or normative (a thesis about what legal actors should do). On this point, see Ratti (2009, 142ff.). Finally, as stressed by Ratti and Ferrer Beltrán, in some passages, Marmor seems to concede that clear normative formulations can also be defeated under non-normal circumstances, and this permits a reductio ad absurdum of his theses, see Ratti (2009, 162ff), Ferrer Beltrán and Ratti (2012, 30ff.).

12 The definitions of 'legal interpretation' range from 'the process (or activity) that recognizes or discovers the linguistic meaning or semantic content of the legal text' (Solum 2010, p. 96), to the 'seek[ing] its authors' intended meaning' (Alexander 2011, p. 87) and to the activity which 'is required only when the formulation of the rule leaves doubts as to its application in a given set of circumstances' (Marmor 2005, p. 118).
} 
'legal interpretation' is ambiguous, since it can refer to an inner mental activity, to a public, rational justification of an interpretative conclusion, to one or more interpretative arguments employed in such a justification ${ }^{13}$ or, again, to an interpretative outcome.

For my purpose, it is important to distinguish between legal interpretation as an argument (or a chain of arguments) and legal interpretation as an interpretative outcome. For example, by 'literal interpretation' one can refer to the interpretative criterion that prescribes to interpret words-or sentences-according to their literal meaning. Alternatively, by 'literal interpretation' one can refer to the interpretative conclusion justified by appealing to a literal argument, i.e. the outcome that consists in interpreting a sentence according to its literal meaning. An interpretative argument is a general pattern that prescribes to satisfy certain criteria $C$ in ascribing meaning to legal texts. An interpretative outcome is the class of all the interpretative conclusions that share certain common features $(F s) .{ }^{14}$ Usually, there is precise match between interpretative argument(s) and interpretative outcome(s), but it is not a one-to-one correspondence. The same interpretative outcome-as a token — can be justified by different and concurrent interpretative arguments. For example, a given literal interpretative outcome can be justified by both a literal argument and a systematic argument.

I consider an argument as 'interpretative' if, within a certain legal culture, it is usually employed in order to ascribe meaning to legal provisions. Analogously, an outcome is 'interpretative' if it amounts to an ascription of meaning to a legal provision. These definitions are deliberately generic: they cast no light on the nature of the legal interpretation, its criteria of correctness and its limits. As we have seen, the formalistic approach is now discredited, but many other alternatives remain openfrom sceptical approaches that there are no correct solutions, to positions that equate legal interpretation with ordinary understanding and to theories that give precedence to moral arguments. However, solving these disputes is outside the scope of this essay. For my purposes, it is sufficient to focus on those arguments and results that are considered as interpretative within a given legal culture.

In my view, a defeasible interpretation is just a particular interpretative outcome, and from this idea, some interesting consequences come to light. As Guastini notes, 'it makes no sense to ask whether legal rules (either some of them or all of them) are

\footnotetext{
${ }^{13}$ Following widespread legal use, I will employ the expressions 'legal interpretative arguments', 'legal interpretative criteria', and 'legal interpretative cannons' as synonyms.

14 The definitions in the text concern interpretative arguments and interpretative outcome as types. By contrast, an interpretative argument as a token is an instantiation of a given general pattern. More precisely, an argument-token is a particular argument according to which in order to satisfy $C$, a given legal provision $p$ must be understood as expressing the norm $n$-and/or the term $t$ in $p$ must be interpreted as $m$. For example, the argument according to which 'things' must be understood as referring to 'inanimate objects' is a particular application of the general pattern according to which words have to be interpreted according to their literal meaning. An interpretative outcome as a token is a member of a given class of interpretative outcomes. For example, the interpretative conclusion according to which the legal provision 'No vehicles in the park!' expresses the norm 'No means of carrying or transporting something shall be taken into the park' is a member of the general class of the interpretative outcomes that share the features of ascribing to words and/or sentences their literal meaning.
} 
defeasible or not. Rules — or, better, rule formulations, poor devils — are inert, they do nothing: they let themselves be defeated, but do not defeat themselves' (Guastini 2012, p. 190). Therefore, the first issue listed above (Sect. 1) — that is, whether all legal norms are defeasible, whether defeasibility is a feature that distinguishes rules from principles or whether no legal norm is defeasible-is poorly formulated. A proper formulation may be to ask whether legal interpreters, and judges in particular, interpret-or are authorised to interpret—all kinds of legal provisions introducing implicit exceptions to their literal meanings. The answer can only be contingent. ${ }^{15}$

Now, one could be tempted to redefine 'defeasibility' as the class of the interpretative outcomes that share the common feature of adding implicit exceptions- that could not be exhaustively listed ex ante-to the literal meaning of a legal provision. In the following sections, I will argue that this redefinition is not so plain as it firstly appears.

\subsection{About the Notion of Literal Meaning}

What is meant by 'literal meaning'? The definition of literal meaning has been highly debated and strongly criticised both in philosophy of language (Searle 1978, 1980; Rommetveit 1988; Ariel 2002; Recanati 2004) and in legal theory (Poggi 2013; Butler 2016; Ramirez Ludeña 2018). Many authors have argued that the notion of 'literal meaning', understood as purely a semantic and contextual meaning, is useless, empty or-at best-highly undetermined. Someone may reply that although this could be true in many cases, defeasibility relates to legal provisions whose literal meaning is clear and sufficiently determined. In my view, this reply can also be challenged.

The norm defeated is often obtained by a universal quantification, or-in Schauer's words (1991) - by an entrenched generalisation of its factual predicate. ${ }^{16}$ However, it seems to me that this generalisation cannot be considered as a strictly literal interpretation of the provision at hand. In fact-as Rodríguez (2012) claims and contrary to Schauer's view-the indiscriminate generalisation of all legal rules would produce counterintuitive consequences. So, for example, if the legal provision

\footnotetext{
${ }^{15}$ Cf. Schauer (1998, p. 236) points out that defeasibility is not a necessary feature of legal rules but a contingent aspect of certain decision-making systems. In the same sense, Marmor (2016) argues that 'courts typically have a kind of quasi-legislative power to add items to any list of an unless clause in a legal rule, thus modifying the condition for the rule's applicability' (26). And, as the previous examples show (Sect. 2), in the majority of the actual legal systems, as a matter of fact, a defeasible interpretation is not peculiar to principles: both the norm formulations of rules and the norm formulations of principles are interpreted in that peculiar, non-literal way. Therefore, as claimed by Sartor (1995, p. 144), defeasibility is not a feature that distinguishes rules from principles.

${ }^{16}$ According to Schauer (1991), 'Any rule can be reformulated to take the form of a hypothetical factual predicate followed by a consequent' (Schauer 1991, p. 23). The hypothetical factual predicate is a descriptive generalisation specifying the conditions under which the consequent must follow. Schauer claims that legal rules are entrenched generalisations, resisting any malleability. This means that when the factual predicate occurs the consequent must ever follow. Legal rules are treated by decisionmakers as 'having the power to provide a reason for decision even when the instantiation [of the generalization] does not serve its generating justification' (Schauer 1991, p. 76). On Schauer's theory see also Sect. 4.1 below.
} 
'The murderers must be punished' were to be understood as 'All the murderers must be punished', this would lead to a conflict with the norm 'Murderers that act for selfdefence must not be punished'. ${ }^{17}$

In other words, interpreting a legal provision $(S)$ as if it would include a universal quantifier makes sense only if after recognising the sub-system of the relevant legal provisions, we verify that there is not another legal norm $(N)$ that provides a different legal effect when the factual predicate provided by $S$ occurs with other factual elements. For example, it makes sense to interpret 'The murderers must be punished' as 'All the murderers must be punished' only if we have verified that there is not another legal norm $(N)$ that provides a different legal effect when the factual predicate provided ('to be a murderer') occurs together with other elements, e.g. acting for self-defence. In my view, this amounts to saying that the generalisation of the factual predicate of a legal norm is not a literal interpretation in either of the two senses distinguished above (Sect. 3.1). First, it is not a literal interpretative outcome because the universal quantifier is not, strictly speaking, within the letter. Second, it is not the outcome of a literal interpretative argument because we can include the universal quantifier only after a systematic interpretation of the relevant legal provisions.

The defeated norm is not drawn from a literal argument, but, in some cases, it is the exception that is derived from a literal argument. Consider the caseUnited States vs. Church of the Holy Trinity (Sect. 2), which is usually taken as a paradigmatic example of legal defeasibility. In this case, the judges also invoked a literal argument in favour of their decision. The Supreme Court, arguing from the title of the statute, ${ }^{18}$ claimed that: 'The common understanding of the terms 'labor' and 'laborers' does not include preaching and preachers, and it is to be assumed that words and phrases are used in their ordinary meaning' (p. 143 U. S. 460).

From the above arguments, it may be argued that the norm defeated is not a literal meaning but rather a prima facie, intuitive (possibly non-literal), plain and somehow obvious meaning (see, e.g., Ratti 2009, p. 146). This approach, however, makes the theoretical framing of defeasibility even more uncertain. What is the 'intuitive', 'prima facie' and 'plain' meaning of a legal provision is, as a matter of fact, controversial (see, e.g., Sullivan 2000; Nourse 2011). ${ }^{19}$

\footnotetext{
17 More precisely, this result occurs if we understand the universal quantifier 'all' in the sense that a given factual predicate is a necessary and sufficient condition for a given legal consequence. The topic is related to the strengthening of the antecedent in law: considering factual predicate as a necessary and sufficient condition implies, inter alia, making such reinforcement possible. As Rodriguez claims, strengthening the antecedent implies that 'two logically independent conditions cannot imply contradictory normative consequences' (Rodríguez 2012, p. 94), but this is exactly what occurs with the example in the text.

18 The title of the statute was 'An act to prohibit the importation and migration of foreigners and aliens under contract or agreement to perform labor in the United States, its territories, and the District of Columbia'.

19 In her milestone work, Sullivan (2000) argues that the plain meaning doctrine is just a way to cheat with statutory interpretation, which is a form of misrepresentation used to make choice look like choicelessness and to make discretion look like a constraint. Sullivan offers many examples and arguments to show how, behind the formula of plain meaning, discretionary choices are concealed, starting from the
} 


\subsection{About the Notion of Exception}

The supporters of the traditional notion of 'defeasibility' assume that the concept of exception is clear, but it is not. In particular, the border between exceptions and negative elements is doubtful. In this regard, the so-called incorporationist view claims that exceptions are always negative element. ${ }^{20}$ For example, according to this view, self-defence is a negative element of murder (as well as of many other offences), and we can rephrase the crime of murder by including - besides its positive elements (to kill a human being, to intend to kill him/her, etc.) - the negative element of the absence of self-defence, as well. This explains why, according to incorporationists, explicit exceptions do not pose any problem: only implicit exceptions are puzzling in so far as they are not predictable ex ante. ${ }^{21}$

The incorporationist approach was criticised by D'Almeida (2015), who convincingly shows that there is a difference-a legal, important difference-in considering something as an exception or as a negative element. What changes is the burden of proof. In particular, D'Almeida claims that the positive and negative elements of the offence ( $P$-facts, in D'Almeida's words) are those facts that must be proven in order to issue a correct judgement in favour of the prosecutor, while the exceptions ( $D$-facts, in D'Almeida's words) are those facts that must not be proven in order to issue a correct judgement in favour of the prosecution. ${ }^{22}$ Therefore, against the supporters of the incorporationist thesis, D'Almeida argues that exceptions are not merely negative elements. For example, the absence of self-defence is not a negative element of murder because it is not the case that it must be proven in order to issue a correct judgement in favour of the prosecutor. Instead, the absence of consent is a negative element of rape because it must be proven in order to issue a correct judgement in favour of the prosecutor. Therefore, if we endorse D'Almeida's view, we must specify if the notion of legal defeasibility refers to exceptions—as D'Almeida claims - or to negative conditions or to both.

\footnotetext{
Footnote 19 (continued)

identification of the text to be interpreted, to the reconstruction of the co-text and to the reference to different types of meaning. In particular, she identifies five different kinds of meaning to which the 'plain meaning' formula can refer. Nourse (2011), in contrast, distinguishes between only two different meanings of 'plain meaning' - namely ordinary/popular meaning and expansive/legalist meaning—which are both employed in case law.

${ }^{20}$ The incorporationist view is supported among others by Mackie (1955, p. 32), Moore (1981, p. 238), MacCormick (1995, p. 100), Atria (2001, p. 124-125, 137-138), Rodríguez (2003), Chiassoni (2012, p. 175), Waluchow (2012, p. 260).

21 Therefore, according to the incorporationist view, in all the above examples (Sect. 2), the implicit exceptions are nothing but implicit negative conditions of the legal consequences. Thus, for example, we can reformulate the federal law discussed in Holy Trinity Church vs. U.S. by saying that the necessary and sufficient conditions for applying the sanction are paying for the passage of an alien employee, who is not a pastor, from a foreign country to the U.S. Or we can reformulate the criminal norm about defamation by saying that the necessary and sufficient conditions of the sanction are communicating with more people, offending the reputation of another person and not saying something true and in the public interest.

${ }^{22}$ The role of the burden of proof in legal defeasibility has been stressed also by other authors (MacCormick 1995; Sartor 1995; Prakken 2001; Prakken and Sartor 2004; Hage 2003; Sartor 2006) but in different ways: see D'Almeida (2015), passim.
} 


\subsection{About Implicit Exceptions}

If the notion of exception is unclear, the notion of implicit exception is not free from problems either. An exception can be 'implicit' in the following different senses at least. (i) It can be implicit that a given fact or circumstance is an exception, i.e. it is not expressly qualified as an 'exception', and perhaps it may be doubtful whether it is a negative element. ${ }^{23}$ (ii) The norm to which something is an exception can be implicit, i.e. the general norm respect to which another norm is an exception is not expressly identified. (iii) The content of the exception can be implicit, i.e. we know that there are exceptions, but they are not expressly identified. ${ }^{24}$ (iv) The legal source of the exception can be implicit, i.e. the norm that establishes the exception is somehow an implicit norm.

In legal literature, this problem has been rarely addressed, but different authors seem to embrace different notions of 'implicit' exception. Dolcetti and Ratti (2016), for example, limit the notion of defeasibility only to those exceptions that derive from implicit principles. Therefore, according to them, an exception is implicit if its source is implicit. ${ }^{25}$ D'Almeida (2015) seems to consider mainly the exceptions whose content is implicit. ${ }^{26}$ Finally, Chiassoni considers an exception as implicit if it is not qualified as such, or, more precisely, if it "cannot be read into [the text of the] legal provision' which it defeats (Chiassoni 2019, p. 249).

\subsection{About Unpredictability}

Finally, it is not clear what is meant by saying that implicit exceptions cannot be exhaustively listed ex ante or, which seems the same, that implicit exceptions are not foreseeable or predictable ex ante. The predictability ex ante is diachronically changing and synchronously gradual. An exception can be predictable and, as a matter of fact, expected at a certain time and not at another. It can be foreseen by few or many depending on variables that mainly concern judicial precedents, legal theses, widespread legal or political or moral values.

\footnotetext{
${ }^{23}$ Consider, e.g. the famous English case Edwards (R v Edwards [1975], QB 27). The Court of Appeal established that on a charge of selling intoxicating liquor without a justices' licence-an offence under Section 160(1)(a) of the Licensing Act 1964-it is not for the prosecutor to prove that the defendant had no licence but for the defendant to prove that she had (i.e. that 'not having a licence' is not a negative element of the offence, but instead 'having a licence' is an exception). Williams (1988) criticizes this decision and attempts to demonstrate that the absence of a licence should have been regarded as an integral part of the offence - as a negative element—and, therefore, it should have been proved by the prosecutor.

${ }^{24}$ Think of indeterminate provisions such as 'unless a more serious offence has been committed' or 'unless there are serious grounds of public policy or security'.

${ }^{25}$ See below Sect. 4.2.

${ }^{26}$ According to D'Almeida, the judge is authorised to introduce an implicit exception if (1) her decision would otherwise contravene an evaluative standard $S$ due to some (proven) circumstances that are different from $P$-facts and (2) the judgment described in (1) could consistently be accepted by someone who thinks that, ceteris ignotis, if the circumstances above did not occur, the decision would not contravene the standard S (D'Almeida 2015, p. 176).
} 
Recall the previous example of the paternity denial (Sect.2). The fact that the (plain, intuitive) meaning of the legal provision about the paternity denial does not apply in case of the heterologous fertilisation was not foreseeable in 1942, when this provision was enacted, because the Italian constitution was not still in force and because heterologous fertilisation does not still exist. However, it was certainly foreseeable, and it had been foreseen, before the constitutional judgment in 1998. This example may suggest restricting the notion of 'exception not predictable ex ante' only to those exceptions that the normative authority could not foresee due to factual reasons. In fact, some authors specify the widespread notion of defeasibility by adding that the implicit exceptions have to occur under unusual circumstances, ${ }^{27}$ and a way to clarify this requirement may be by referring to circumstances that were not predictable at the time of enactment due to scientific progress. ${ }^{28}$ However, a defeasible interpretation is not the only possible outcome of the inadequacy of law with respect to scientific progress. Often, this inadequacy produces gaps-sometimes filled by analogy and sometimes in a different way.

\section{The Many Faces of Legal Defeasibility}

At this point, one may wonder why we do not redefine the widespread notion of legal defeasibility by resolving all the difficulties that I have previously pointed out. The usefulness of such an operation obviously depends on our purposes. I will argue that if our aim is to investigate legal argumentation, such work is not useful because the label 'defeasibility' covers heterogeneous phenomena. More precisely, legal defeasibility refers to interpretative outcomes deriving from interpretative arguments that, on the one hand, are very different from one another and, on the other, are employed also to ground different interpretative outcomes.

This thesis must be argued accurately, since it contradicts a widespread view about legal defeasibility.

It has been frequently argued that legal defeasibility derives from the need to avoid absurd results. ${ }^{29}$ A defeasible interpretation is justified when the application of a given legal provision in its meaning $N$ to a particular case would produce a result that is absurd and undesirable from a legal point of view. In order to avoid this result from occurring, an exception must be introduced. According to this view, what characterises legal defeasibility is not only its outcome but also its source-that is, the kind of problem that it is called to solve. Moreover, this source is mirrored by a specific interpretative argument. In fact, in order to justify a defeasible interpretation, judges must appeal to pragmatic argumentation (better known as an 'argument from absurdity'), which consists in referring 'to the consequences of applying a rule in a specific case' (Feteris 2016, p. 61).

\footnotetext{
27 See, e.g., MacCormick (1995), Alchourrón (1996b), MacCormick (2005, 241), Sartor (2006).

28 Ratti terms this notion 'empirical defeasibility' (see Ratti 2009, 153ff.).

29 See, e.g., MacCormick (1978, p. 251), Sartor (1995), Schauer (1998), Bayón (2000), Bix (2012), Sartor (2012), Schauer (2012).
} 
I agree that the justifications of defeasible interpretative outcomes fit with the general argument scheme of pragmatic argumentation. ${ }^{30}$ However, in the case of legal defeasibility, this scheme obscures some important differences.

First, the absurdity that the defeasible interpretations aim to prevent can take very different forms. More precisely, as we will see in the next sections, such an absurdity can consist of different kinds of conflicts. ${ }^{31}$ The conflicts in question are very different from each other, and, therefore, defeasibility does not have a unique source. Moreover, sometimes these conflicts are solved differently, i.e. sometimes their solution does not amount to defeating a norm.

Second, in order to solve such conflicts, very different arguments are invoked. In fact, the argument from absurdity is not an autonomous interpretative argument. It can support the conclusion that a given meaning is not to be ascribed to a given legal provision. In order to justify which meaning is to be ascribed, other arguments must come into play. As far as a defeasible interpretation, it can be supported by a variety of arguments. Not one of these arguments has a special relationship with legal defeasibility, in the sense that they all are also often invoked to justify different interpretative outcomes. Whatever interpretative outcome these arguments are called to justify, they always pose the same theoretical problems. Such problems vary from one argument to another, but, generally speaking, they are all connected to the notion of legal interpretation, its limits and its distinction from law-creating power.

If the above points are correct, it follows that from the standpoint of legal argumentation, there is nothing peculiar in legal defeasibility. The expression 'legal defeasibility' refers to a class of interpretative outcomes that have many different sources and are justified through many different arguments. Surely, these arguments generate some problems, but these problems are nothing but the well-known problems related to legal interpretation and interpretative arguments. They are not special problems connected to only legal defeasibility.

\footnotetext{
${ }^{30}$ On this scheme, see Van Eemeren and Grootendorst (1992), Feteris $(2002,2016)$. On the different meanings of 'absurdity' in law, see Dougherty (1994).

${ }^{31}$ On the contrary, Feteris maintains that 'In the law the desirability or undesirability of a particular result is evaluated in the light of the goal of the rule' (Feteris 2016, p. 67). I think that in the case of legal defeasibility, this claim is not correct. As we will see, sometimes the absurdity is justified by reasons others than the purpose of the norm. For example, in the case of defamation, there was no room for appealing to the purpose of the criminal provision-especially because the criminal provision was enacted under the fascist regime, when the freedom of the press was not guaranteed and it did not matter whether the news was true or not. Actually, Feteris seems to conflate the argument from purpose with other different arguments. She writes, 'In legal theory this argumentation that refers to the goal or purpose is often characterized as argumentation from coherence with certain legal purposes, goals, policies and values' (Feteris 2016, p. 67). However, the interpretative argument focused on the purpose of a single norm is very different and poses different problems from the argument based on the coherence with legal values. In the first case, the problem is how to understand and identify the purpose; in the second one, the problem is how to identify the values involved and/or how to solve the conflicts among different values. I think that Feteris is right in claiming that in law 'pragmatic argumentation forms part of a complex argumentation. The complexity is related to the fact that the (un)desirability of the consequences is part of the general argument scheme of pragmatic argumentation' (2016, p. 77). Nevertheless, in the case of legal defeasibility, appealing to the purpose of the norm is one way among many to justify the (un) desirability in question.
} 


\subsection{Conflict with Underlying Internal Justification}

According to the first approach, endorsed, for example by Frederick Schauer (1991, 1998, 2012), the absurdity, which legal defeasibility prevents, derives from a conflict between the literal meaning of a legal provision and its underlying justification. Consider the example of Bologna's barber: here, one can argue that the underlying internal justification of the prohibition clearly does not apply to the barber's case. ${ }^{32}$ Therefore, Schauer claims that:

....a rule is defeasible when its application is contingent upon the non-occurrence of an unspecifiable list of very good reasons for not applying the rule, such reasons having strength greater than would have been sufficient for those reasons to determine the outcome in the absence of the rule (Schauer 1998, 238).

Schauer's account raises several problems, but I am not interested in discussing them here. ${ }^{33}$ I only want to stress three points.

First, the interpretative argument that appeals to an underlying internal justification of the rule, in order to bring out an absurdity and avoid it, can lead to interpretative outcomes that are different from the introduction of an implicit exception. Consider, for example, par. 575 of the Italian Penal Code, which punishes for murder 'anyone who causes the death of a man'. What about who causes the death of a woman? To exclude women from the scope of this provision would be, in a sense, absurd, so 'man' is intended to be synonymous with 'human being'. In this example, appealing to the underlying internal justification of the rule leads to an extensive interpretative outcome.

Second, the interpretative argument that appeals to the underlying internal justification of the rule always presents the same problems, even when it does not lead to a defeasible interpretation. The underlying internal justification of a rule can be difficult to identify: its identification depends on interpretative choices, and it is itself the product of a certain interpretation. Moreover, as some authors have noticed (Ferrer Beltrán and Ratti 2012; Rodriguez 2012; Sardo 2014), it is also difficult to decide when the reasons to defeat the literal meaning are 'very good' - that is, when they have sufficient strength.

Third, as we will see, sometimes a defeasible outcome arises from different sources, and it is justified by different arguments.

\footnotetext{
32 Schauer (1998, pp. 117-118) distinguishes between external defeasibility-that occurs when a rule is overridden by particular factors external both to the rule and to its justification-and internal failure of a rule, when a rule is not applicable to those cases in which the justification does not apply. Schauer observes that while external defeasibility does not pose serious problems, a rule with no resistance to internal failure whatsoever will not deserve, in an important sense, the name of a 'rule'.

${ }^{33}$ For some criticisms see Atria (2001, 112ff.), Ferrer Beltrán and Ratti (2012), Rodríguez (2012), Sardo (2014).
} 


\subsection{Conflict with Implicit Principles}

Dolcetti and Ratti (2016) argue that defeasibility can be understood as the outcome of a particular type of normative conflict: the conflict between a norm, $N 1$, logically derived from an explicit norm, and a norm, $N 2$, logically derived from an implicit principle, which is solved in favour of the second. For example, the case United States vs. Church of the Holy Trinity is framed by Dolcetti and Ratti as the outcome of the conflict between (i) the norm NI, 'It is prohibited to pay the passage to any worker, including pastors'; and (ii) the norm $N 2$, 'It is permissible to pay for the passage for a pastor'. The norm $\mathrm{Nl}$ is derived from the express provision that prohibits employers from paying for the passage of an alien employee from a foreign country to the U.S. for the purpose of taking up employment. Instead the norm $N 2$ is derived by a bulk of free-floating standards - amongst which the underlying justification of the rule, aiming at discouraging the hiring of cheap labour force and the favour for religious practices. The conflict has been resolved with the prevalence of $N 2$.

According to Dolcetti and Ratti, the absurdity, which defeasibility is called to avoid, is properly speaking a kind of normative conflict: a conflict among norms, one of which is implicit. If we take Dolcetti and Ratti's proposal as a lexical definition of 'defeasibility', it is clearly false. As a matter of fact, legal theorists also speak of defeasibility when what is involved is not a conflict with an implicit principle (or norm). ${ }^{34}$ Instead, if we take Dolcetti and Ratti's proposal as a redefinition of 'defeasibility', as a linguistic theoretical proposal, they have to demonstrate why it is appropriate and advantageous.

However, it seems to me that the salient feature of Dolcetti and Ratti's proposal consists in focusing the notion of defeasibility on the construction of implicit principles, ${ }^{35}$ which is a complicated and highly discretional construction. It is worth noting that that construction always gives rise to the same problems, even when jurists employ an implicit principle for purposes other than defeating a literal meaningfor example, in order to choose between two literal interpretations of the same legal provisions or to expand the literal meaning. ${ }^{36}$ Again, the interpretative argument that justifies a defeasible interpretation is not peculiar: sometimes, it is invoked to justify different interpretative outcomes, and it always poses the same problems.

\footnotetext{
${ }^{34}$ Also in United States vs. Church of the Holy Trinity, one can doubt that implicit principles were involved, since, in U.S., freedom of religion is expressly stated by the First Amendment.

35 As is well known, the distinction between rules and principles is problematic and highly controversial: this topic is beyond the scope of this essay. Here I use the term 'principle' in a untechnical way in order to refer to generic, widely applicable and high-value norms, which are usually qualified as principles by the jurisprudence of the country in question.

${ }^{36}$ For example, in the famous Italian case Englaro (Corte Cass. judgement n. 21748/2007), judges argued for the existence in Italian law of an implicit principle, the freedom to dispose of one's body, in order to justify an extensive interpretation of the civil legal provisions about the guardian's powers.
} 


\subsection{Conflicts with Dogmatic Assumptions}

According to Guastini $(2010,2012)$, 'defeasibility' is just a novel name for a very well-known technique of construction: restrictive interpretation. Guastini argues that, frequently, the absurdity that defeasibility is called upon to resolve consists of an inconsistency between a norm and a dogmatic construction. Recall the example of the presidential power of veto over parliamentary statutes. Guastini claims that according to a literal interpretation, any parliamentary statute is can be vetoed. However, jurists defeat this literal norm, arguing in the following ways. (i) Two kinds of parliamentarian statutes are to be distinguished, ordinary and constitutional statutes. (ii) In the existing constitutional system, the president of the republic is not the head of the executive branch-she is a neutral power, whose function is just guaranteeing the constitution. (iii) Therefore, the function of veto power is to allow the president to exercise a priori control over the constitutionality of statutes. (iv) However-so the argument runs-constitutional statutes are not required to comply with the constitution, since they are constitutional amendments that can derogate the constitution. (v) Therefore, the constitutional provision at hand ought to be interpreted as referring only to ordinary statutes, and it says nothing about the veto power over constitutional statutes. (vi) Thus, the conclusion is that the president has no veto power over constitutional statutes.

In this example, it may seem that the inconsistency arises among constitutional norms. However, it should be noted that some of the 'norms' involved are actually what Guastini labels 'dogmatic assumptions'. Thus, proposition (ii), according to which the president of the republic is a neutral power, "is not a strictly interpretative thesis, but rather a "dogmatic" one-a thesis of so-called "constitutional theory", if one prefers' (Guastini 2012, p. 183). It is not a legal norm (either explicit or implicit); it is a widespread assumption among the constitutional theory of the country in question. If we delete that dogmatic assumption, no inconsistency arises.

Examining the dogmatic assumptions and the problems they pose is beyond the scope of this essay. Here, it is sufficient to stress that they play an important role within legal interpretation, and they often justify different interpretative outcomes. For example, dogmatic assumptions can justify the thesis according to which the same term has a different meaning within civil and criminal law, and, in some countries, they justify the thesis according to which criminal intention also covers oblique intention (Vorsatz vorliegen). Once again, the dogmatic argument does not have a special connection with defeasible interpretation.

\subsection{Conflicts Among Principles of the Same Legal Degree}

Sometimes, defeasibility is the outcome of the balancing among conflicting principles that have the same legal force-typically, two constitutional principles. Usually, what happens is that a certain interpretation of a legal provision, $A$, is consistent with a certain constitutional principle, $P 1$, but not consistent with another constitutional principle, $P 2$. Therefore, it is argued that between these two principles, there 
is a conflict, which has to be solved by balancing them and establishing the prevalence of one of them in that single case, i.e. with respect to the case regulated by $A$. Sometimes, but not always, the outcome of such a balance can consist of defeating the 'plain' meaning expressed by $A$. Think of the aforementioned example of the Italian offense of defamation. In these hypotheses, the absurdity to avoid is, therefore, a peculiar conflict among principles of the same legal degree.

Defeasibility is only one of the possible outcomes of the balance between principles. At other times, the conflicts among principles are resolved simply by stating the prevalence of the principle $P l$ and by not modifying the meaning of provision $A$ or by stating the prevalence of the principle $P 2$ and, thus, by declaring $A$ unconstitutional. In every case, the balance between principles always poses the same problems. In particular, the main issue seems to be to tie the balance to some meta-criteria in order to limit the judges' discretion.

\subsection{Conflicts with Superior Explicit Principles}

It seems to me that defeasible interpretations often derive from a conflict between an explicit rule and an explicit principle. More precisely, it is a way to resolve an inconsistency between the meaning of a legislative provision and an explicit constitutional principle. In these cases, defeasibility is the outcome of a so-called constitutionally oriented interpretation-that is, the interpretative argument according to which a legal provision, which potentially expresses more than one norm, must be interpreted as expressing the meaning that does not conflict with a certain interpretation of a constitutional principle. Here, the absurdity at stake is, more precisely, an unconstitutionality. Recall the example of the paternity denial: the Italian Constitutional Court adopted a defeasible interpretation because otherwise the legal provision would have violated a series of constitutional principles.

It is worth noting that the constitutionally oriented interpretation does not always produce a defeasible interpretation. Its outcome can also consist of the choice of one of the meanings made available by a systematic interpretation, ${ }^{37}$ or of the assignment of a broader meaning than the plain one ${ }^{38}$ or even in the introduction of criteria not literally provided. ${ }^{39}$

\footnotetext{
37 For example, the Italian legal provisions on support administration have been interpreted, according to systematic criteria, both as allowing the judicial procedure to appoint the support administrator without the defence lawyer of the person and as imposing such a defence lawyer. The Italian Constitutional Court (ordinance no. 128/2007) ruled that only the second interpretation can be considered constitutionally compliant and should, therefore, be preferred. See also Corte di Cassazione judgement no. 25366/2006.

${ }^{38}$ For example, the Italian Constitutional Court ruled that par. 187 of the new Highway Code (Driving While Intoxicated by Drugs)—establishing that 'Anyone driving in conditions of physical and mental deterioration associated with the use of narcotic or psychotropic substances [...] shall be punished with the penalties provided by Article 186, paragraph 2'-refers both to the sanctioning treatment (the penalties in a strict sense) and the jurisdiction. Otherwise, the offense established by par. 187 would fall under the jurisdiction of a different judge than the similar offence provided by par. 186 (Driving While Intoxicated by Alcohol), and this would violate a number of constitutional principles - especially the principle of equality (par. 2 Italian Constitution). See Constitutional Court judgement no. 133/2007.

39 So, for example, many criminal provisions, enacted before the 1948 Italian Constitution, sanctioned hypotheses of strict liability, but today, they are unanimously interpreted as requiring at least the agent's negligence. Otherwise, they would be unconstitutional.
} 
Here again, there is nothing that characterises defeasibility but its peculiar outcome: the introduction of an exception to the somehow intuitive meaning of a given legal provision.

\section{Defeasibility as Logical Reasoning?}

At this point, one can object that there is something that all the previous interpretations have in common: they fit into the same reasoning schemata; namely, they are examples of non-monotonic reasoning. In fact, to add an exception to a normative premise is tantamount to treating that premise as a defeasible conditional-that is, a conditional respect to which neither modus ponens nor the strengthening of the antecedent hold and which, therefore, is subject (by definition) to a non-monotonic logic (if any). ${ }^{40}$

There are several ways to construct a non-monotonic logic suitable for legal reasoning, and a great deal of formal frameworks has been devised to capture and represent defeasible inferences in the legal domain. A detailed analysis of these issues is beyond the scope of this work, so I will limit myself to some general observations.

Some non-monotonic schemata embrace a notion of 'defeasible premise' that is very similar to the most widespread notion analysed above, re-proposing all the problems already listed and suggesting a formalist approach to legal interpretation. The same holds for the accounts that connect legal defeasibility to an epistemic deficit. ${ }^{41}$ These approaches cloud the role of legal interpretation, suggesting that defeasibility is just a matter of knowledge-of knowing pre-existing norms or exceptions, correct legal solutions and facts. ${ }^{42}$ In this regard, I think that the very idea that a 'Legal conclusion derived by means of non-monotonic inferences can be defeated by further information' (Sartor 1995, p. 142) is somehow misleading. Legal defeasibility is not a matter of information in a strict sense.

Legal defeasibility is very different from epistemic defeasibility, since no new knowledge can directly defeat a given legal norm. ${ }^{43}$ If I believe that all birds fly,

\footnotetext{
${ }^{40}$ Actually, this thesis is disputed: some authors claim that the logic of open-ended exceptions to legal rules need not defy monotonicity. See Soeteman (2003), Alchourrón (1993), Hage (2003), Holton (2011), Marmor (2016).

${ }^{41}$ In fact, it is argued that defeasible reasoning is due to the provisional nature of human knowledge. Therefore, a Herculean judge would not resort to defensible reasoning, nor would a Herculean legislator enact defeasible norms, although some authors think that this would not be useful. Cf. Sartor (2012, p. $133)$.

${ }^{42}$ See Sartor (2006, p. 9): 'My view is that an exception is effective (it has an impact on the legal states of affairs, on the law as an "institutional reality"), even when the judge has not yet established it (and even when the issue on the existence of such an exception will never be brought to the attention of a judge)'. According to Sartor, this is connected to the ontic aspect of defeasibility: 'there are facts (empirical or institutional states of affairs or events) that are normally sufficient to determine certain legal or moral outcomes, but can be made irrelevant (undercut) or can be outweighed (rebutted) by other facts' (Sartor 2006, p. 10).

${ }^{43}$ For different arguments on the distinction between legal and epistemic defeasibility see Hage (2003).
} 
but then I discover Tweety, which is a penguin and cannot fly, my new knowledge directly defeats my previous belief. I'm compelled to change my previous belief, since from the standpoint of classic logic, 'All birds fly' and 'Some birds do not fly' cannot be both true. By contrast, if I believe that 'Whoever drew blood in the streets should be severely punished', and then I discover that Mario the barber has opened by mistake the vein of one of his client in the square, this new knowledge does not compel me to revise my previous belief. Discovering the case of Tweety is the same as knowing that there is an exception to the fact that all birds fly. In contrast, knowing the case of Mario is not the same as discovering a norm that states an exception. This does not mean to say that new information does not play any role into the legal argumentation about defeasibility, but it is a very indirect, possible and complex role. ${ }^{44}$ New information may induce judges to change their previous interpretation of the legal provision by changing the set of arguments that justified it. Judges may say that the legal provision is no longer to be intended in its literal meaning, but, instead, it must be interpreted according to its internal justification as 'Whoever intentionally and/or during a physical aggression drew blood in the streets should be severely punished'. Or they may not. Just as the repealed rule is not simply discovered, so is the exception. Both are the products of discretional interpretations.

Surely, there are also other non-monotonic schemata more suitable for legal reasoning-for example, schemata that aim to diachronically represent the judicial reasoning and do not assume that the defeasible norm-premise is the sole meaning of a given provision or equate the construction of the implicit exception with a discovery. These schemata surely can capture judicial changes in legal interpretation: they are different but not abstractly inconsistent with the approach for which I have tried to argue. $^{45}$ Nevertheless, from my point of view, sometimes they suffer from certain limitations.

The most common definitions of non-monotonic logic are not totally suitable for the legal domain. Consider the following definitions: ' $[\mathrm{N}]$ on-monotonic logic is [...] that kind of inference in which reasoners draw conclusions tentatively, reserving the right to retract them in the light of further information' (Strasser and Antonelli 2018); 'a reasoning schemata is defeasible if one should, under conditions, refrain from adopting its conclusions though endorsing its premises' (Sartor 2012, p. 112); and 'the outcome of defeasible reasoning [...] [is] a pro tanto conclusions, namely, a conclusion which, through being justified on the basis of the information so far considered, may be withdrawn on the basis of further information' (Sartor 2012, p. 117). These definitions imply (i) that from a potentially defeasible premise (say: $p$, then $q$ ) can follow only a pro tanto conclusion ( $p$, then pro tanto $q$ ) and (ii) that

\footnotetext{
44 This point is clearly addressed by MacCormick (1995). According to MacCormick, legal defeasibility is not merely a problem of knowledge: 'Discretion of some sort is involved here [...] there are objective factors here, but they are necessarily mediated through judicial subjectivity. The process is one of determination, not of deduction' (MacCormick 1995, p. 108).

45 Moreover, non-monotonic schemata meant to capture the shift of the burden of proof from one party to other in legal reasoning have been developed [see, e.g., Prakken (2001), Sartor (2006)]. These schemata refer to what is sometimes called 'procedural defeasibility' (Rodríguez 2017) or 'process-based defeasibility' (Prakken and Sartor 2004). The analysis of this field of investigation is beyond the scope of this essay.
} 
when a defeasible premise ( $p$, then $q$ ) is, in fact, defeated ( $p$, but not $q$ ), it is, however, still endorsed. Both implications are doubtful as far legal practice is concerned. If we admit, as most authors do, that all legal norms are defeasible, ${ }^{46}$ it follows that all the normative conclusions are only pro tanto conclusions. However, this idea sounds somehow odd and counterintuitive. Surely, judges do not think of themselves as someone who draws conclusions tentatively, reserving the right to retract them.

Even when a defeasible norm is, in fact, defeated, it seems that it can still justify an ultimate, not pro tanto, conclusion. Thus, for example, if judges have decided that the Bologna statute does not apply to the barber, the norm at stake can still justify the conclusion that John, who beat and shed the blood of Bill, must be condemned. Surely, this decision could be wrong — maybe John did not beat Bill—but it does not seem a provisional verdict that judges have stated only pro tanto, reserving the right to withdraw it.

Moreover, when a legal norm-premise is, in fact, defeated, it is no longer endorsed: in other words, the defeasible outcome concerns the normative premise in first place, and not the conclusion. For example, when the judges decided that the crime of defamation does not exist when the news is true and in the public interest, they changed the meaning of the legal provision that operates as a premise. From that moment onwards, the meaning of the normative provision was no longer that 'anyone who communicating with more people offends the reputation of another person must be sentenced for defamation', but that 'anyone who communicating with more people offends the reputation of another person must be sentenced for defamation except when the news is true and in the public interest'. The first norm is not still endorsed, only the text, the legal provision, is not changed.

I admit that the aforementioned problems can be overcome by sufficiently sophisticated formalisations. However, it is important to notice that, as Sartor states, 'The legal application of non-monotonic logics (like any other formal methods) presupposes a fundamental operation that remains outside the logic apparatus: the legal interpretation of the texts' (Sartor 1995, p. 140). My point is precisely that legal interpretation plays a fundamental role in what is called 'legal defeasibility', and that if we focus on the interpretative arguments that are employed to justify defeasible outcomes, it emerges that they are not at all peculiar. ${ }^{47}$ This point does not

\footnotetext{
${ }^{46}$ For example, according to Sartor (2012, passim), every legal norm is defeasible, as if in every norm the adverb 'normally' was implied. In the same sense, MacCormick states that 'implicit defeasibility afflicts all instances of legal institutions' (MacCormick 1995, p. 100).

47 For example, Hage (2003) distinguishes five concepts of defeasibility (i.e. ontological, conceptual, epistemic, justification and logical defeasibility) and argues that justification defeasibility is the phenomenon that plays a role in legal reasoning: 'Justification defeat concerns the question whether a belief is justified relative to one's belief set, where the contents of the belief set are not specified. It occurs because of changes in the belief set, with the effect that a belief that was justified relative to the old belief set is not justified relative to the new belief set' (Hage 2003, p. 225). According to Hage, justification defeat especially plays a role in the context of discovery, that is, in the justification of the applicable legal norm ('CLCP'). The process of identification and justification of the applicable norm ('CLCP') from legal sources 'involves defeasible reasoning, because taking a new rule into consideration may bring about that a CLCP which was justified in the light of the sources that were originally taken into consideration is not justified anymore' (Hage 2003, p. 230). Hage's perspective is surely suitable for legal defeasibility and does not involve all the problems outlined in the text. However, according to my perspective,
} 
prevent-once norms have been expressed and once the provision has already been interpreted - the intervention of a logical (non-monotonic) formalisation ${ }^{48}$

\section{Conclusions}

In this essay, I have claimed that the most widespread definition of 'legal defeasibility' is inaccurate and misleading: in particular, it hides the close relationship between legal defeasibility and legal interpretation. However, we do not need to refine it, since the label 'defeasibility' covers such different phenomena that it lacks any explanatory power. Surely, that label always refers to a peculiar interpretative outcome-that is, the inclusion of an implicit exception (in some sense of 'implicit' and of 'exception') to a somehow clear, plain meaning expressed by a certain legal provision. Nevertheless, apart from this outcome, the phenomena under consideration are very different: they generate from different kinds of conflict, they are the products of different interpretative arguments and they pose different problems. Thus, the role of dogmatic assumptions poses different problems than the constitutionally oriented interpretation, the (often not logical) construction of implicit principles or the resolution of a conflict between principles of equal legal force. Moreover, each one of these interpretative processes presents significant analogies with others (other cases of constitutionally oriented interpretations, constructions of implicit principles, etc.), whose outcomes do not consist of a defeasible interpretation.

In conclusion, I think that the problems traditionally associated with legal defeasibility must be turned into problems relating to legal interpretation and specific interpretative arguments. Surely, the latter problems are complex as the former ones, and this essay does not aim to solve them. However, I believe that this move has the advantage of conceptual clarity and parsimony. Framing a problem is always the first step to solve it.

One can object that in this essay, I miss the point of the legal debate on defeasibility - that is, the great challenge that defeasibility poses for the rule of law principle.

Footnote 47 (continued)

what produces a change in the belief set-i.e. in the set of legal sources-is precisely a change into the interpretative arguments. For example, a given legal norm ('CLCP'), which is identified and justified in virtue of a set (S1) consisting of a legal provision $p$ plus a literal argument, is not identified and justified in virtue of another set consisting of the same provision $p$ plus an argument that appeals to the underlying justification of $p$.

${ }^{48}$ In other words, the interpretative processes on which I have focused in the previous paragraphs are different from the inferential processes studied by legal logicians: the former consist of the reasons for justifying a defeasible interpretive result; the latter of the analysis is what follows when these reasons are (or may be) accepted or advanced. 
However, I contend that to adhere, for first time, to a defeasible interpretation is not more dangerous - from the perspective of the rule of law-than to make a judicial revision by abandoning a consolidated non-literal interpretation in favour of a literal one. Additionally, from this perspective, there is nothing special about legal defeasibility. I think that legal interpretation, in general, is a theoretical challenge for the rule of law. If we admit that there is not only one interpretation-that interpretative activity is always discretional-then we have to define its criteria of acceptability, tracing the boundary between interpretation and creation, in order to save the rule of law. I claim that this task can be best done if we focus on the interpretative arguments rather than on some of their outcomes.

Acknowledgements Earlier versions of this essay was delivered at $\mathrm{PaGe}$, Palermo-Genova Phd workshop, University of Palermo, and at a seminar which took place at the University of Bologna. I thank all the members of the audience for discussion, and in particular Alberto Artosi, Bruno Celano, Isabel Fanlo Cortés, Pablo Moreno Cruz, Giovanni Sartor, Corrado Roversi, Michele Ubertone, Vito Velluzzi, Annalisa Verza and Vittorio Villa for their precious suggestions and criticisms.

Funding Open access funding provided by Università degli Studi di Milano within the CRUI-CARE Agreement. This work was funded by Harmonia, Polish National Centre for Science (Grant No. 2018/30/M/HS5/00254) and MIUR (Grant No. FFABR2017).

Open Access This article is licensed under a Creative Commons Attribution 4.0 International License, which permits use, sharing, adaptation, distribution and reproduction in any medium or format, as long as you give appropriate credit to the original author(s) and the source, provide a link to the Creative Commons licence, and indicate if changes were made. The images or other third party material in this article are included in the article's Creative Commons licence, unless indicated otherwise in a credit line to the material. If material is not included in the article's Creative Commons licence and your intended use is not permitted by statutory regulation or exceeds the permitted use, you will need to obtain permission directly from the copyright holder. To view a copy of this licence, visit http://creativecommons.org/licen ses/by/4.0/.

\section{References}

Alchourrón, Carlos E. 1993. Philosophical foundations of deontic logic and the logic of defeasible conditionals. In Deontic logic in computer science, ed. John-Jules Meyer and Roel Wieringa, 43-84. Chichester: Wiley.

Alchourrón, Carlos E. 1996a. Detachment and defeasibility in deontic logic. Studia Logica 57: 5-18.

Alchourrón, Carlos E. 1996b. On law and logic. Ratio Juris 9: 331-348.

Alchourrón, Carlos E., and Eugenio Bulygin. 1996. Norma jurídica. In El derecho y la Justicia. Enciclopedia Iberoamericana de filosofía, ed. Eernesto Garzón Valdés and Francisco J. Laporta, 133-141. Madrid: Trotta.

Alexander, Larry. 2011. Simple-minded originalism. In The challenge of originalism: Theories of Constitutional Interpretation, ed. Grant Huscroft and Bradley W. Miller, 87-98. Cambridge: Cambridge University Press.

Ariel, Mira. 2002. The demise of a unique concept of literal meaning. Journal of Pragmatics 34: 361-402.

Atienza, Manuel, and Juan Ruiz Manero. 1998. A theory of legal sentences. Dordrecht: Kluwer.

Atienza, Manuel, and Juan Ruiz Manero. 2012. Rules, principles, and defeasibility. In The logic of legal requirements, ed. Jordi Ferrer Beltrán and Giovanni Battista Ratti, 238-253. Oxford: Oxford University Press.

Atria, Fernando. 1999. Legal reasoning and legal theory revisited. Law and Philosophy 18: 537-577.

Atria, Fernando. 2001. On law and legal reasoning. Oxford-Portland: Hart Publishing. 
Barnes, Annette. 1988. On interpretation: A critical analysis. New York: Basil Blackwell.

Bayón, Juan Carlos. 2000. Derrotabilidad, indeterminación del derecho y positivismo jurídico. Isonomía 13: 87-117.

Bayón, Juan Carlos. 2002. Why is legal reasoning defeasible? Diritto e questioni pubbliche 2: 1-18.

Bix, Brian H. 2012. Defeasibility and open texture. In The logic of legal requirements, ed. Jordi Ferrer Beltrán and Giovanni Battista Ratti, 193-201. Oxford: Oxford University Press.

Butler, Brian. 2016. Law and the primacy of pragmatics. In Pragmatics and law. Philosophical perspectives, ed. Alessandro Capone and Francesca Poggi, 1-13. Dordrecht: Springer.

Chiassoni, Pierluigi. 2012. Defesibility and legal indeterminacy. In The logic of legal requirements, ed. Jordi Ferrer Beltrán and Giovanni Battista Ratti, 151-192. Oxford: Oxford University Press.

Chiassoni, Pierluigi. 2019. Interpretation without truth. Cham: Springer.

D'Almeida, Luís Duarte. 2015. Allowing for exceptions. A theory of defences and defeasibility in law. Oxford: Oxford University Press.

Dolcetti, Andrea, and Giovanni Battista Ratti. 2016. La derrotabilidad jurídica como relación sistemática compleja. Analisi and diritto 2016: 35-44.

Dougherty, Veronica M. 1994. Absurdity and the limits of literalism: Defining the absurd result principle in statutory interpretation. The American University Law Review 44: 127-166.

Dworkin, Ronald. 1977. Taking rights seriously. London: Duckworth.

Ferrer Beltrán, Jordi, and Giovanni Battista Ratti. 2009. Validità e defettibilità nel diritto. In Norme, principi e logica, ed. Giovanni Battista Ratti, 249-273. Aracne: Roma.

Ferrer Beltrán, Jordi, and Giovanni Battista Ratti. 2012. Deafeasibility and legality: A survey. In The logic of legal requirements, ed. Jordi Ferrer Beltrán and Giovanni Battista Ratti, 11-38. Oxford: Oxford University Press.

Feteris, Eveline T. 2002. A pragma-dialectical approach of the analysis and evaluation of pragmatic argumentation in a legal context. Argumentation 16: 349-367.

Feteris, Eveline T.. 2016. Prototypical argumentative patterns in a legal context: The role of pragmatic argumentation in the justification of judicial decisions. Argumentation 30: 61-79.

Gales, Tammy, and Lawrence M. Solan. 2020. Revisiting a classic problem in statutory interpretation: Is a minister a laborer? Giorgia State University Law Review 36: 491-533.

Guastini, Riccardo. 2010. Defettibilità, lacune assiologiche ed interpretazione. Revus 14: 57-72.

Guastini, Riccardo. 2012. Defeasibility, axiological gaps, and interpretation. In The logic of legal requirements, ed. Jordi Ferrer Beltrán and Giovanni Battista Ratti, 182-192. Oxford: Oxford University Press.

Hage, Jaap. 2003. Law and defeasibility. Artificial intelligence and law 11: 221-243.

Hart, Herbert L.A.. 1948. The ascription of responsibilities and rights. Proceeding of the Aristotelian Society 49: 171-194.

Hernandez Marín, Raffael. 2012. Defeasible properties. In The logic of legal requirements, ed. Jordi Ferrer Beltrán and Giovanni Battista Ratti, 137-150. Oxford: Oxford University Press.

Holton, Richard. 2011. Modeling legal rules. In The philosophical foundations of language in the law, ed. Andrei Marmor and Scott Soames, 165-183. Oxford: Oxford University Press.

Koons, Robert, 2017. Defeasible reasoning. In The Stanford encyclopedia of philosophy, ed. N. Zalta, https://plato.stanford.edu/archives/win2017/entries/reasoning-defeasible/. Accessed 27 April 2020.

Lance, Mark, and Margaret Little. 2008. From particularism to defeasibility in ethics. In Challenging moral particularism, ed. Vojko Strahovnik, Matjaz Potrc, and Mark Norris Lance, 53-74. London: Routledge.

MacCormick, Neil. 1978. Legal reasoning and legal theory. Oxford: Oxford University Press.

MacCormick, Neil. 1995. Defeasibility in law and logic. In Informatics and the foundation of legal reasoning, ed. Zenon Bankowski, Ian White, and Ulrike Hahn, 99-117. Dordrecht: Kluwer.

MacCormick, Neil. 2005. Rhetoric and the rule of law: A theory of legal reasoning. Oxford: Oxford University Press.

Mackie, J.L. 1955. Responsibility and language. Australasian Journal of Philosophy 33: 143-159.

Makinson, David. 2005. Bridges from classical to nonmonotonic logic. London: King's College Publication.

Marmor, Andrei. 2005. Interpretation and legal theory. Oxford: Hart publishing.

Marmor, Andrei. 2016. Defeasibility and pragmatic indeterminacy in law. In Pragmatics and law. Philosophical perspectives, ed. Alessandro Capone and Francesca Poggi, 15-32. Dordrecht: Springer.

Moore, Michael S.. 1981. The semantics of judging. Southern California Law Review 54: 151-294.

Nourse, Victoria. 2011. Two kinds of plain meaning. Brooklyng Law Review 76: 997-1005. 
Nute, Donald, ed. 1997. Defeasible deontic logic. Dordrecht: Kluwer Academic Publisher.

Nute, Donald. 2003. Defeasible logic. In INAP 2001. LNCS (LNAI), vol. 2543. Oskar Bartenstein, et al., 151-169. Heidelberg: Springer.

Pérez Bermejo, Juan Manuel. 2012. Principles, conflicts, and defeats: An approach from a coherentist theory. In The logic of legal requirements, ed. Jordi Ferrer Beltrán and Giovanni Battista Ratti, 288308. Oxford: Oxford University Press.

Pollock, John L. 1987. Defeasible reasoning. Cognitive science 11: 481-518.

Poggi, Francesca. 2007. Semantics, pragmatics, and interpretation. A critical reading of some of Marmor's Theses. Analisi and Diritto 2007: 159-178.

Poggi, Francesca. 2013. The myth of literal meaning in legal interpretation. Analisi and Diritto 2013: 313-335.

Prakken, Henry. 2001. Modelling defeasibility in law: Logic or procedure? Fundamenta Informatica 48: 253-271.

Prakken, Henry, and Giovanni Sartor. 2004. The three faces of defeasibility in the law. Ratio Juris 17: $118-139$.

Pufendorf, Samuel. 1688. De jure naturae et gentium libri octo. Oxford: Clarendon Press.

Ramirez Ludeña, Lorena. 2018. The meaning of "literal meaning." Analisi and Diritto 2018: 83-101.

Ratti, Giovanni Battista. 2009. Norme, principi e logica. Roma: Aracne.

Ratti, Giovanni Battista. 2015. Two conceptions of legal system. Ragion pratica 34: 179-200.

Recanati, François. 2004. Literal meaning. Cambridge: Cambridge University Press.

Redondo, Maria Cristina. 1997. Teorías del derecho y indeterminación normativa. Doxa 20: 177-196.

Redondo, Maria Cristina. 2012. Reasons for action and defeasibility. In The logic of legal requirements, ed. Jordi Ferrer Beltrán and Giovanni Battista Ratti, 309-323. Oxford: Oxford University Press.

Rodríguez, Jorge. 2002. Lógica de los sistemas jurídicos. Madrid: Centro de estudios políticos y constitucionales.

Rodríguez, Jorge. 2003. Derotabilidad e indeterminación del derecho. Respuesta a Juan Carlos Bayón. In Relevancia normativa en la justificación de las decisiones judiciales, ed. Juan Bayón and Jorge Rodríguez, 209-262. Bogota: Univesidad Externado de Colombia.

Rodríguez, Jorge. 2012. Against defeasibility of legal rules. In The logic of legal requirements, ed. Jordi Ferrer Beltrán and Giovanni Battista Ratti, 89-107. Oxford: Oxford University Press.

Rodríguez, Jorge. 2017. Defeasibility and burden of proof. Materiali per una storia della cultura giuridica 47 : 243-258.

Rommetveit, Ragnar. 1988. On literacy and the myth of literal meaning. In The written world, ed. Roger Säljö, 13-40. Berlin-Heidelberg: Springer.

Ross, William David. 1930. The right and the good. Oxford: Clarendon Press.

Sardo, Alessio. 2014. Defettibilità, ideologia, contesto. In Teoria del diritto e analisi logica, ed. Jorge Rodríguez, 55-71. Madrid: Marcial Pons.

Sartor, Giovanni. 1995. Defeasibility in legal reasoning. In Informatics and the foundation of legal reasoning, ed. Zenon Bankowski, Ian White, and Ulrike Hahn, 119-157. Dordrecht: Kluwer.

Sartor, Giovanni. 2006. Syllogism and defeasibility: A comment on Neil MacCormick's rhetoric and the rule of law. EUI Working Papers Law 23: 1-13.

Sartor, Giovanni. 2012. Defeasibility in legal reasoning. In The logic of legal requirements, ed. Jordi Ferrer Beltrán and Giovanni Battista Ratti, 108-136. Oxford: Oxford University Press.

Schauer, Frederick. 1991. Playing by the rules. Oxford: Clarendon Press.

Schauer, Frederick. 1998. On the supposed defeasibility of legal rules. Current Legal Problems 48: 223-240.

Schauer, Frederick. 2012. Is defeasibility an essential property of law? In The logic of legal requirements, ed. Jordi Ferrer Beltrán and Giovanni Battista Ratti, 77-88. Oxford: Oxford University Press.

Searle, John R. 1978. Literal meaning. Erkenntnis 13: 207-224.

Searle, John R. 1980. The background of meaning. In Speech act theory and pragmatics, ed. M. Bierwisch, et al., 221-232. Dordrecht-Boston-London: D. Reidel Publishing Company.

Solum, Lawrence B. 2010. The interpretation-construction distinction. Constitutional commentary 27: 95-118.

Soeteman, Arend. 2003. Legal logic? Or can we do without? Artificial Intelligence and Law 11: 197-210.

Strasser, Christian, Antonelli, G. Aldo. 2018. Non-monotonic logic. In The Stanford encyclopedia of philosophy (Summer 2018 Edition), ed. Edward N. Zalta, https://plato.stanford.edu/archives/sum2018/ entries/logic-nonmonotonic/. Accessed 5 January 2020. 
Sullivan, Ruth. 2000. The plain meaning rule and other ways to cheat at statutory interpretation. In Les certitudes $d u$ droit/Certainty and the law, ed. Ejan Mackaay, 151-188. Montreal: Les Éditions Thémis.

Sunstein, Cass R. 2015. There is nothing that interpretation just is. Constitutional Commentary 30: 193-212.

Swain, Marshall. 1974. Epistemic defeasibility. American Philosophical Quarterly 11: 15-25.

Tarello, Giovanni. 1980. L'interpretazione della legge. Milano: Giuffrè.

Van Eemeren, Frans H., and Rob Grootendorst. 1992. Argumentation, communication, and fallacies. A pragma-dialectical theory of argumentation. Hillsdale, NJ: Erlbaum.

Waluchow, Wil J. 2012. Defeasibility and legal positivism. In The logic of legal requirements, ed. Jordi Ferrer Beltrán and Giovanni Battista Ratti, 254-267. Oxford: Oxford University Press.

Williams, Glaville. 1988. The logic of "Exceptions." Cambridge Law Journal 47: 261-295.

Publisher's Note Springer Nature remains neutral with regard to jurisdictional claims in published maps and institutional affiliations. 